\title{
Evaluation of Physico-Mechanical and Antimicrobial Properties of Gelatin- Carboxymethyl Cellulose Film Containing Essential Oil of Bane (Pistacia atlantica)
}

\author{
Milad Ranjbar ${ }^{1}$, Mohammed Hussain Azizi ${ }^{2 *}$, Adel Mirmajidi Hashtjin ${ }^{3}$ \\ 1- Graduated MSc in Food Science and Technology, Azad University, North Tehran Branch, Tehran, Iran. \\ 2- Department of Food Science and Technology, Tarbiat Modares University,Tehran,Iran. \\ 3- Assistant Prof, Agricultural Engineering Research Institute, Agricultural Research, Education and Extension Organization (AREEO), Karaj, Iran.
}

\section{A B S T R A C T}

Background and Objectives: Microbial activity is the main factor in spoiling food products, which not only changes their texture and taste but also causes economic damage and poisoning. The present study aimed to assess the effects of essential oil of Bane (Pistacia atlantica) on physico-mechanical and antimicrobial properties of gelatin- carboxymethyl cellulose film.

Materials and Methods: The solutions $(4 \% \mathrm{w} / \mathrm{v})$ of gelatin and CMC $(1 \% \mathrm{w} / \mathrm{v})$ were prepared in deionized water. Then different levels of essential oil $(0,03 \%, 0.6 \%$, and $0.8 \%)$ were added to the solutions. Then the films were prepared by casting. The methods of physico-mechanical and antimicrobial evaluation were done based on previous research.

Results: The results showed significant reduction in water vapor permeability, the thickness of film, tensile strength and solubility by increasing essential oil, while the percentage increased $(P<0.05)$. In addition, $L^{*}, a^{*}$ and $b^{*}$ were altered due to the color nature of essential oil of Bane. Increasing essential oil of Bane significantly inhibited the growth of Escherichia. coli, Salmonella enterica, Staphylococcus aureus, and Clostridium sporogenes. High concentrations of bane produced holes in the culture medium, the treatment containing $0.3 \%$ essential oil of bane only resulted in inhibition of Salmonella enterica, whereas higher concentrations of essential oil inhibited bacteria growth entirely.

Conclusions: Essential oil of Bane improved the mechanical properties and inhibitory effects in regards to growth of microorganisms.

Keywords: Edible Film, Gelatin, Bane, Antimicrobial Features, Essential Oil

\section{Introduction}

Biopolymers are efficient substrates to improve the function of pragmatic compounds such as antioxidant and antibacterial materials. In this regard, Conventional food packaging has no competition with edible films $(1,2)$. Carboxymethyl cellulose (CMC) is a cellulose derivative, produced by Carboxymethyl (-CH-COOH) instead of some hydroxyl groups $(\mathrm{OH})$, which is obtained by a reaction of cellulose, sodium hydroxide, and chloroacetic acid. One of the main weaknesses of the CMC is high water vapor permeability. Various studies with presenting different strategies have been conducted on reducing the permeability of edible films (3). Protein plays a significant role in creating the edible films and has a high resistance to penetration of $\mathrm{O} 2, \mathrm{CO} 2$ and oils particularly in low relative humidity. Gelatin is a protein derived from hydrolyzing the collagen in bone and skin. It is used in film production and applied as a carrier for bioactive compounds (3). Most polymers are not able to create optimal and practical films on 
their own and they need to combine with others, which makes a synergic impact and covers their weaknesses (4). Some pragmatic substances along with main components of edible films can be used to improve film efficiency to conserve the food products. Today, it is focused on naturally antimicrobial compounds, which cease the growth of microbes and improve the quality of food products. Hydrophilic compounds extracted from plants enable them to penetrate the lipid membranes of bacteria and fungi and lead to penetration and leakage by disrupting the lipid structure of cell. Extensive leakage of critical molecules and ions from bacterial cells results in killing these microorganisms (5). Besides, main compounds extracted from plants have desirable anti-insect and anti-parasitic characteristics. Different studies have shown the importance of medicinal plants to remove insects, plant and human parasites. The main mechanisms disrupt the respiratory system and skin absorption which consequently results in death of insects and parasites (1). Using antimicrobial and anti-parasitic compounds in edible films does not require the use of thermal processes, destroying the food characteristics $(6,7)$. Packaging type by antimicrobial substances is a strategy to improve food safety and quality. Packaging without antimicrobial materials are susceptible to bacterial and fungal contamination and subsequently leads to low quality of food $(8,9)$.

Bane (Pistacia atlantica) is a native tree species in Iran, its fruit has been used in traditional herbal medicine. Recently, the studies on P. atlantica have shown that its resin is a rich source for destroying Streptococcus mutants, Staphylococcus aureus, Salmonella enterica, Bacillus cereus, Escherichia coli, Helicobacter pylori, mold and yeast. So resin derivatives of Bane can be used as a rich source of antimicrobial compounds in food industry $(10,11)$. Chromatography results show that compounds such as alpha-pinene and beta-pinene are the most important components of Bane extract, which can penetrate the lipid membrane of bacteria and fungi and subsequently leading to permeability and leakage $(12,13)$. The objective of this study was therefore to examine the influence of antimicrobial properties of essential oil of Bane and its application on physical properties of optimized film consisting of gelatin and CMC.

\section{Materials and Methods}

Material: The materials used in the study were purchased as a follow: Gelatin (Qazvin, Iran), CMC (Santos, Japan), glycerol (Merck, Germany), Tween 80 (Sigma-Aldrich), essential oils of Bane (Van Sanandaj, Iran), Escherichia coli, Staphylococcus aureus, clostridium. Sporogenes and Salmonella enterica (organization of scientific and industrial research, Iran), Trytone yeast extract agar (Merck, Germany), lactose broth (Merck, Germany), Plate Count Agar (Merck, Germany) and RCM (Merck, Germany).

Protocol for preparing the edible coating of gelatin-CMC: Preparation of the film was done according to the method described by SánchezGonzález et al. (1972) with some modifications. First, the solution $(4 \% \mathrm{w} / \mathrm{v})$ of gelatin was prepared in deionized water and then stirred at $80^{\circ} \mathrm{C}$ for $30 \mathrm{~min}$. When it was completely dissolved to reach ambient temperature, $30 \%$ glycerol (90\% purity) was added to this solution as a plasticizer and stirred for $10 \mathrm{~min}$. $1 \mathrm{~g}$ of CMC was dissolved in $100 \mathrm{ml}$ of distilled water alone and $0.5 \mathrm{~g}$ glycerol was added as a softener. Finally, the final solution was prepared based on 50\% gelatin stock solution and 50\% CMC stock solution $(\mathrm{w} / \mathrm{w})$. The $\mathrm{pH}$ of solution was adjusted in the range of 5-5.5 to make complex concertation between gelatin and CMC. Afterwards, it was stirred for 10 min. The essential oil of Bane $(0.3,0.6$, and $0.8 \%)$ was added to the mixture solution. Since essential oils are insoluble in water, $1 \%$ Tween 80 was added to the mixture. Then, it was homogenized for 4 min using... Samples were placed in stationary mode to cool and leave air bubbles. Then the film was prepared by casting. After drying the film at ambient temperature, it was placed in oven at $37^{\circ} \mathrm{C}$ for $20 \mathrm{hr}$. (14).

Water vapor permeability: Water vapor permeability (WVP) was determined based on ASTM E96-80 (15). For this purpose, glassy cups with an internal diameter of $5.5 \mathrm{~cm}$ and a height of $3.5 \mathrm{~cm}$ were used. Cups contained $8 \mathrm{ml}$ of distilled water that it can make $100 \%$ humidity inside the cups. Film samples were placed on cups by melt paraffin and were sealed with rubber gaskets and clamps. Afterwards, the cups were placed in a desiccator. we were weighed every 12 hours and the weight loss was determined using a digital scale as well as calculating the water vapor permeability from the following equation: 
$W V P=\frac{\Delta \mathrm{M} \times \mathrm{X}}{\mathrm{A} \times \Delta \mathrm{T} \times \Delta \mathrm{P}}$

Where, $\Delta \mathrm{M}$ is weight loss of a cup, $\mathrm{A}$ is exposed area of $23.74 * 10^{-4} \mathrm{M}^{2}, \Delta \mathrm{T}$ is time, $\Delta \mathrm{P}$ is minor pressure difference between internal and external part of cup, which is $3.170 \mathrm{KPa}$ in $100 \%$ humidity.

Measuring the film thickness: The thickness of film was calculated by a digital micrometer $(0.001 \mathrm{~mm}$, MITUTOYO of Japan). The repetition was performed in 5 points of a sample (1).

Elasticity test: The elasticity was determined at a testing speed of 50mm min 1 using Hounsfield H5KS tensile testing equipment. The average of five dumbbell shaped samples was taken as the value for each compound (16).

Solubility: For this purpose, $2 \times 3 \mathrm{~cm}$ pieces of the film were cut and stored in desiccator for 7 days. After that, the samples were weighed and deionized in beakers containing 80 c.c. of water. Samples were shaken at $50 \mathrm{rpm}$ and $25^{\circ} \mathrm{C}$, then unresolved parts in an oven at $60^{\circ} \mathrm{C}$ were dried up to reach constant weight, subsequently were weighted and solubility was determined from the following equation (14):

Solubility Percent $=\frac{\text { first weight }- \text { second weight }}{\text { first weight }} \times 100$

Color test: The sample color was recorded by HunterLab (CR 400, Minolita, Japn) as CIELAB including $L^{*}$ (light), $a^{*}$ (red-green), $b^{*}$ (yellow-blue). Colorimeter was calibrated using black and white tiles before testing. Film samples were set in six different angles and their parameters were measured. Total colorimetric difference $(\Delta \mathrm{E})$ for each sample compared to control was calculated using the following equation:

$$
\Delta E=\sqrt{\left(\Delta L^{*}\right)^{2}+\left(\Delta a^{*}\right)^{2}+\left(\Delta b^{*}\right)^{2}}
$$

Where, $L_{0}{ }^{*}, a_{0}{ }^{*}$ and $b_{0}{ }^{*}$ were respectively recorded as $92.23,-1.29$, and 1.19 . In addition $L^{*}, a^{*}$ and $b^{*}$ belonged to color parameters of samples (15).

Antimicrobial activity of films: Agar diffusion method was used to determine the antimicrobial activity of the film. Films were formed as discs with a diameter of $20 \mathrm{ml}$ by template. Discs were placed on medium in sterile conditions. In this study, Escherichia coli (PTCC 1338), Staphylococcus aureus (PTCC 1431), Salmonella Entrica subsp (PTCC1709), and Clostridium sporogenes
(PTCC1651) were evaluated as a microbial test (Microbial vials were prepared from Merck company). Plate Count Agar, Lactouse Broth, Trytone, Yeast Extract Agar, and RCM were respectively used for Escherichia Coli, Salmonella Entrica, Staphylococcus aureus, and Clostridium sporogenes. For this purpose, discs were set on medium in sterile condition then the halo diameter was measured by a caliper. Moreover, a sterile plate was applied to prove the lack of contamination of culture media. Each plate was filled with $10^{7} \mathrm{CFU} \mathrm{ml}{ }^{-1}$ of the mentioned bacteria (16).

Statistical analysis: The Data was submitted to factorial as a Completely Randomized Design with four treatments and three replications, and the results were calculated as mean \pm SD. Significant differences were assessed ( $p<0.05$ ) by ANOVA and mean comparison done by Duncan Multiple Range Test. All data were submitted to SAS 9.1 and Excel 2013.

\section{Results}

\section{Physical Features of Gelatin-CMC}

impact of essential oil on the water vapor permeability: Water vapor permeability of optimized film (50-50\%) containing essential oil of Bane was assessed. The results showed that adding essential oil resulted in significant difference in water vapor permeability $(P<0.05)$. According to table 1 , water vapor permeability of control (without essential oil) was more than that in samples treated by essential oil of Bane as the water vapor permeability decreased by increasing essential oil $(P<0.05)$. The maximum and minimum water vapor permeability was obtained in control and samples containing $0.8 \%$ essential oil, respectively.

Table 1. The of control, treatments containing $0.3 \%, 0.6 \%$, and $0.8 \%$ essential oil of Bane

\begin{tabular}{lc}
\hline Treatment & $\begin{array}{c}\text { Water Vapor Permeability } \\
(\mathrm{g} / \mathrm{msPa})\end{array}$ \\
\hline Control (without essential oil) & $2.6 \times 10^{-7} \pm 0.06 \times 10^{-7 \mathrm{a}}$ \\
Treatment 1 (containing 0.3\% essential oil) & $1.34 \times 10^{-7} \pm 0.05 \times 10^{-7 \mathrm{~b}}$ \\
Treatment 2 (containing 0.6\% essential oil) & $1.20 \times 10^{-7} \pm 0.02 \times 10^{-7 \mathrm{c}}$ \\
Treatment 3 (containing 0.8\% essential oil) & $1.06 \times 10^{-7} \pm 0.06 \times 10^{-7 \mathrm{~d}}$ \\
\hline Same letters in a column show no significant difference $(P<0.05)$
\end{tabular}

The effect of essential oil on film thickness: As shown in figure 1 , the thickness of film decreased by increasing essential oil $(P<0.05)$. The highest and lowest thickness belonged to control and $0.8 \%$ essential oil, respectively. no significant difference was found between samples containing essential oil of Bane $(P<0.05)$. 


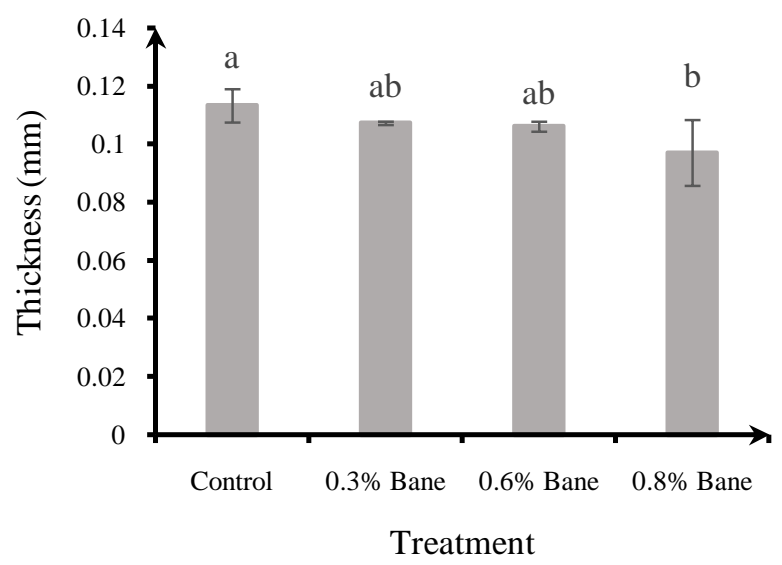

Figure 1. The thickness $(\mathrm{mm})$ of control, treatments containing $0.3 \%, 0.6 \%$, and $0.8 \%$ essential oil of Bane

\section{Impacts of essential oil on elasticity: According to} table 2 and figure 2, adding essential oil had a significant effect on increasing the stretch percent of treatments $(P<0.05)$. Films containing essential oil had low tensile strength and high stretch percent.

Table 2. The elasticity of control, treatments containing $0.3 \%, 0.6 \%$, and $0.8 \%$ essential oil of Bane

\begin{tabular}{lc}
\hline Treatment & Stretch percent $(\%)$ \\
\hline Control (without essential oil) & $53.82 \pm 6.05^{\mathrm{c}}$ \\
Treatment 1 (containing 0.3\% essential oil) & $61.33 \pm 4.75^{\mathrm{bc}}$ \\
Treatment 2 (containing 0.6\% essential oil) & $69.23 \pm 2.73^{\mathrm{b}}$ \\
Treatment 3 (containing 0.8\% essential oil) & $87.92 \pm 2.99^{\mathrm{a}}$ \\
\hline Same letters in a column show no significant difference $(P<0.05)$
\end{tabular}

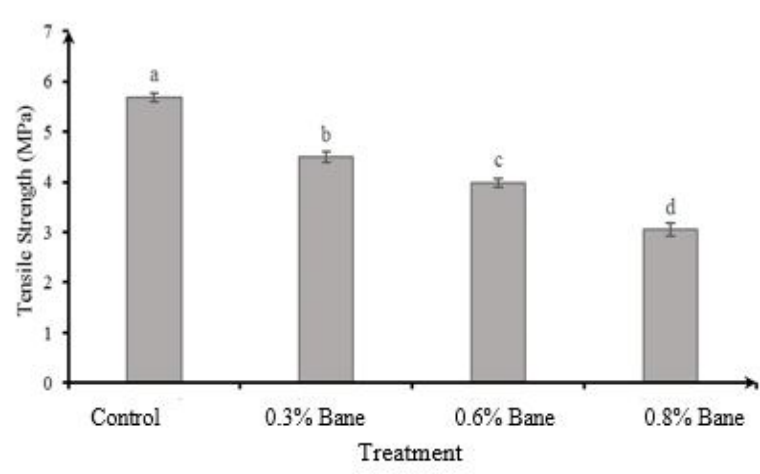

Figure 2. The tensile strength of control, treatments containing $0.3 \%, 0.6 \%$, and $0.8 \%$ essential oil of Bane

Assessing the essential oil of Bane on solubility: Essential oil of Bane significantly affected the solubility of treatments $(P<0.05)$ so that the solubility decreased by increasing the concentration of essential oil (Table 3).

The effect of essential oil on film color: According to figure 3 and table 4 , essential oil of Bane significantly reduced the $L^{*}, a^{*}$, and $b^{*}((P<0.05)$.

The essential oil of Bane decreased light and red intensity of the film, while the intensity of blue color increased by adding essential oil (Figure 3 ).

Antimicrobial property of essential oil: Figure 4 and Table 5 shows the microbial culture on gelatinCMC film containing different levels of essential oil of Bane.

Table 3. The solubility of control, treatments containing $0.3 \%, 0.6 \%$, and $0.8 \%$ essential oil of Bane

\begin{tabular}{lc}
\hline Treatment & Solubility (\%) \\
\hline Control (without essential oil) & $30.19 \pm 0.86^{\mathrm{a}}$ \\
Treatment 1 (containing 0.3\% essential oil) & $22.28 \pm 0.50^{\mathrm{b}}$ \\
Treatment 2 (containing 0.6\% essential oil) & $18.55 \pm 0.57^{\mathrm{c}}$ \\
Treatment 3 (containing 0.8\% essential oil) & $13.28 \pm 0.37^{\mathrm{d}}$ \\
\hline
\end{tabular}

Same letters in a column show no significant difference $(P<0.05)$

Table 4. The Lab (per 100) of control, treatments containing 0.3\%, 0.6\%, and $0.8 \%$ essential oil of Bane

\begin{tabular}{lccc}
\hline Treatment & $\mathrm{L}^{*}$ & $\mathrm{a}^{*}$ & $\mathrm{~b}^{*}$ \\
\hline Control (without essential oil) & $89.40 \pm 0.8^{\mathrm{a}}$ & $-1.29 \pm 0.06^{\mathrm{a}}$ & $4.06 \pm 0.15^{\mathrm{c}}$ \\
Treatment 1 (containing 0.3\% essential oil) & $88.60 \pm 0.1^{\mathrm{ab}}$ & $-1.77 \pm 0.00^{\mathrm{b}}$ & $7.25 \pm 0.01^{\mathrm{b}}$ \\
Treatment 2 (containing 0.6\% essential oil) & $88.12 \pm 0.0^{\mathrm{b}}$ & $-1.80 \pm 0.03^{\mathrm{b}}$ & $4.67 \pm 0.04^{\mathrm{b}}$ \\
Treatment 3 (containing 0.8\% essential oil) & $87.89 \pm 0.2^{\mathrm{b}}$ & $-1.94 \pm 0.03^{\mathrm{c}}$ & $7.76 \pm 0.58^{\mathrm{a}}$ \\
\hline
\end{tabular}

Same letters in a column show no significant difference $(P<0.05)$ 


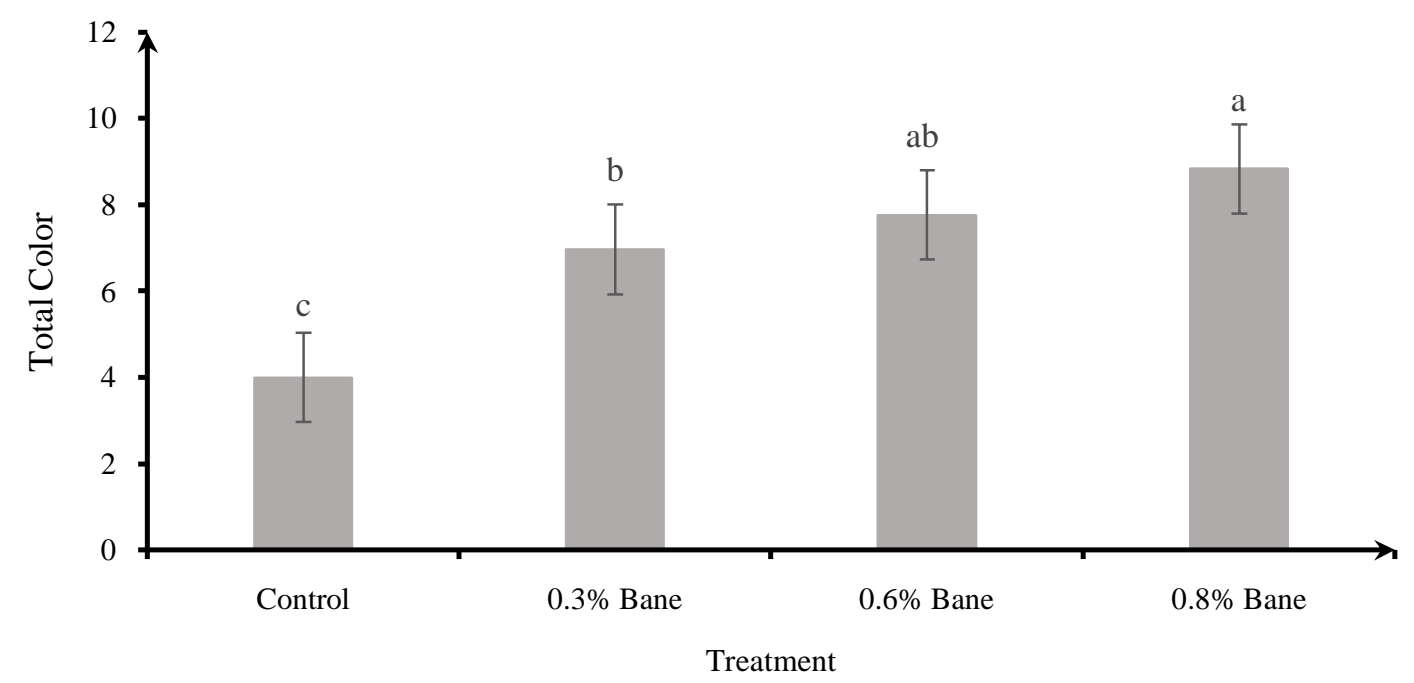

Figure 3. The film color of control, treatments containing $0.3 \%, 0.6 \%$, and $0.8 \%$ essential oil of Bane

Table 5. The microbial culture of control, treatments containing $0.3 \%, 0.6 \%$, and $0.8 \%$ essential oil of Bane (Halo diameter to be $\mathrm{mm}$ )

\begin{tabular}{lcccc}
\hline Treatment & E. coli & C. sporogenes & S. enterica & S. aureus \\
\hline Control (without essential oil) & $0^{\mathrm{c}}$ & $0^{\mathrm{c}}$ & $0^{\mathrm{d}}$ & $0^{\mathrm{c}}$ \\
Treatment 1 (containing 0.3\% essential oil) & $0^{\mathrm{c}}$ & $0^{\mathrm{c}}$ & $5.2^{\mathrm{c}}$ & $0^{\mathrm{c}}$ \\
Treatment 2 (containing 0.6\% essential oil) & $6.8^{\mathrm{b}}$ & $7.5^{\mathrm{ab}}$ & $8.79^{\mathrm{b}}$ & $6.2^{\mathrm{b}}$ \\
Treatment 3 (containing 0.8\% essential oil) & $9.4^{\mathrm{a}}$ & $8.5^{\mathrm{a}}$ & $11.11^{\mathrm{a}}$ & $8.52^{\mathrm{a}}$ \\
\hline
\end{tabular}

Same letters in a column show no significant difference $(P<0.05)$

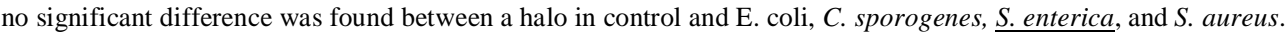

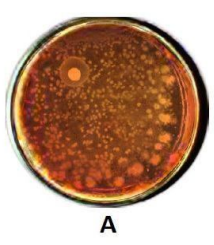

Figure 4. Microbial culture to find halo in the treatment containing $0.8 \%$ essential oil of Bane (A: S. aureus, B: E.Coli, C: Control Sample (without essence), D: $c$. sporogenes E: S. enterica

\section{Discussion}

According to the finding of this study and previous findings of researches, Films containing essential oils due to increase of hydrophobic characteristic were more efficient in terms of water vapor barrier in respect to those without essential oil. Sánchez et al. (2009) reported that density, $\mathrm{pH}$, and water vapor permeability were reduced by increasing essential oil, while viscosity and transparency increased. So it can be concluded that essential oil of Bane due to its hydrophobic property prevents the diffusion of water vapor molecules in the film (17). The research findings showed that the reason of lower thickness of samples containing essential oil is due to the fact that essential oil is in empty spaces between the polymer chains and its hydrophobic nature prevents high moisture by gelatin and CMC $(6,5)$. However, gelatin and $\mathrm{CMC}$ in the film without essential oil can absorb maximum moisture and increase their film thickness with no barrier (4-7). According to table 2 and figure 2 , essential oil significantly reduced the tensile strength $(P<0.05)$. Essential oil disrupted the structural density and reduced tensile strength as well 
as increased stretch percent. Based on different studies, the use of antimicrobial essential oils on different polymers changes the mechanical properties due to exposure to the change in molecular level (16). Sánchez et al. (2009) reported that no significant difference was found in $2 \%$ essential oil in respect to control, while tensile strength and modulus of elasticity significantly decreased (17). Moreover, all essential oils except citronella reduced tensile strength and essential oil of thyme reduced stretch percent up to its breaking point. The films containing essential oil of tarragon was not significantly different compared to others, but other essential oils increased the stretch percent (18). Evaluation of the solubility showed that highest and lowest solubility was obtained in control $(30.39 \%)$ and the treatment containing $0.8 \%$ essential oil (13.6\%), respectively. The reduction of solubility by increasing essential oil is corresponded to hydrophobic and non-polar properties of essential oil of Bane. Maizura et al. (2007) in a study investigating essential oil impact of Andropogon spp on sago starch-alginate films, indicated using this essential oil reduced edible film solubility (19-24). According to the figure 3, the change of film color is correspondent to greenness and blueness of essential oil of Bane. Zinoviadou et al. (2009) concluded that the essential oil of oregano increases the total color and Chroma of whey protein isolate films (19). Microbial culture of film shows that the gelatin-CMC film does not have antimicrobial properties alone and it needs to combine with other substance such as essential oils (19-21). As seen in figure 3 , the treatment containing $0.8 \%$ essential oil had clear halos, which it indicates inhibition of bacteria growth in the presence of essential oil of Bane. In low concentration $(0.3 \%)$ of essential oil only $S$. enterica growth was inhibited, which it shows no effect of film on inhabitation of bacteria growth. However, by increasing essential oil, the growth of bacteria decreased as the highest antimicrobial effect was obtained in the treatment containing $0.8 \%$ essential oil of Bane (20). The antimicrobial property of essential oil of Bane is corresponded to its phenol value. The antimicrobial extracts penetrate to cytoplasmic membrane and collapse ion balance inside the cells and subsequently deposit vital substances in the cells $(21,22)$ According to different researches, the essential oil of Bane trees not only has inhibitory effects, but also has antimicrobial properties on E. coli, C. sporogenes, S. enterica, and S. aureus (10).

\section{Conclusion}

The present study has shown that adding essential oil of Bane to gelatin-CMC film has antimicrobial impacts on E. coli, C. sporogenes, S. enterica, and $S$. aureus. These antimicrobial properties are due to the fact that decreasing water activity of film and growth limitation of microorganisms, also corresponded to its phenol value. The treatment containing $0.8 \%$ essential oil of Bane had the highest inhibitory effect on these bacterial. Hence, according to our results, gelatinCMC (50-50) containing $0.8 \%$ essential oil of Bane can be used for the production of biodegradable packaging film to increase the shelf life of food products.

\section{Financial disclosure}

The authors declared no financial interest.

\section{Funding/Support}

This work was financially supported by the Azad University, North Tehran Branch, Tehran, Iran.

\section{References}

1. Gulluce M, Sahin F, Sokmen M, Ozer H, Daferera D, Sokmen A, Polissiou M, Adiguzel A, Ozkan H. Antimicrobial and antioxidant properties of the essential oils and methanol extract from Mentha longifolia L. ssp. longifolia. Food chemistry. 2007 Dec 31;103(4):1449-56.

2. Ghanbarzadeh B, Almasi H. Physical properties of edible emulsified films based on carboxymethyl cellulose and oleic acid. International journal of biological Macromolecules. 2011 Jan 1;48(1):44-9.

3. Mortazavian S. Azizi A. Sohrabvandi MH. Edible films: qualitative indicators and methods of production. Iranian Journal of Food Science and Technology. 2011 winter, 7(4): 107-117.

4. Asma C, Meriem E, Mahmoud B, Djaafer B. Physicochemical characterization of gelatin-cmc composite edibles films from polyion-complex hydrogels. Journal of the Chilean Chemical Society. 2014 Mar;59(1):2279-83.

5. Hosseini MH, Razavi SH, Mousavi MA. Antimicrobial, physical and mechanical properties of chitosan-based films incorporated with thyme, clove and cinnamon essential oils. Journal of Food Processing and Preservation. 2009 Dec 1;33(6):727-43.

6. Brody AL, Strupinsky EP, Kline LR. Active packaging for food applications. CRC press; 2001 Jun 8.

7. Du WX, Olsen CW, Avena-Bustillos RJ, McHugh TH, Levin CE, Friedman M. Antibacterial Activity against E. coli O157: H7, Physical Properties, and Storage Stability 
of Novel Carvacrol-Containing Edible Tomato Films. Journal of Food Science. 2008 Sep 1;73(7):M378-83.

8. Cutter CN. Opportunities for bio-based packaging technologies to improve the quality and safety of fresh and further processed muscle foods. Meat science. 2006 Sep 30;74(1):131-42.

9. An DS, Kim YM, Lee SB, Paik HD, Lee DS. Antimicrobial low density polyethylene film coated with bacteriocins in binder medium. Food Science and Biotechnology. 2000 Jan;9(1):14-20.

10. Hanafi G. Darvishi N. Ardabili S. Ahmadi F. Antibacterial properties of essential oil of Bane on different bacteria. The Scientific Journal of Kurdistan University of Medical Sciences. 2012; 17: 1-11.

11. Rahimzadeh G. Rokhzadi A. Bahramian S. The effect of essential oil of Bane on lactobacillus bulgaricus. Iranian Journal of Food Microbiology. 2014; 1(1): 49-55.

12. Leite AM, Lima ED, Souza EL, Diniz MD, Trajano VN, Medeiros IA. Inhibitory effect of beta-pinene, alphapinene and eugenol on the growth of potential infectious endocarditis causing Gram-positive bacteria. Revista Brasileira de Ciências Farmacêuticas. 2007 Mar;43(1):121-6.

13. Tohidi M, Khayami M, Nejati V, Meftahizade $H$. Evaluation of antibacterial activity and wound healing of Pistacia atlantica and Pistacia khinjuk. Journal of Medicinal Plants Research. 2011 Sep 9;5(17):4310-4.

14. Sánchez-González L, Vargas M, González-Martínez C, Chiralt A, Cháfer M. Use of essential oils in bioactive edible coatings: a review. Food Engineering Reviews. 2011 Mar 1;3(1):1-6.

15. Lee KY, Shim J, Lee HG. Mechanical properties of gellan and gelatin composite films. Carbohydrate Polymers. 2004 Jun 4;56(2):251-4.

16. Chen $\mathrm{CH}$, Lai LS. Mechanical and water vapor barrier properties of tapioca starch/decolorized hsian-tsao leaf gum films in the presence of plasticizer. Food Hydrocolloids. 2008 Dec 31;22(8):1584-95.

17. Sánchez-González L, Vargas M, González-Martínez C, Chiralt A, Cháfer M. Characterization of edible films based on hydroxypropylmethylcellulose and tea tree essential oil. Food Hydrocolloids. 2009 Dec 31;23(8):2102-9.

18. Pérez-Gago MB, Krochta JM. Lipid particle size effect on water vapor permeability and mechanical properties of whey protein/beeswax emulsion films. Journal of agricultural and food chemistry. 2001 Feb 19;49(2):9961002 .

19. Zinoviadou KG, Koutsoumanis KP, Biliaderis CG. Physico-chemical properties of whey protein isolate films containing oregano oil and their antimicrobial action against spoilage flora of fresh beef. Meat Science. 2009 Jul 31;82(3):338-45.

20. Hosseini F, Adlgostar A, Sharifnia F. Antibacterial activity of Pistacia atlantica extracts on Streptococcus mutans biofilm. Int Res J Biological Sci. 2013 Feb;2(2):1-7.

21. Burt S. Essential oils: their antibacterial properties and potential applications in foods - a review. International journal of food microbiology. 2004 Aug 1;94(3):223-53.

22. Denyer SP, Hugo WB. Biocide-induced damage to the bacterial cyctoplasmic membrane. Society for Applied Bacteriology. Technical Series. 1991; 27: 171-87.

23. Maizura M, Fazilah A, Norziah MH, Karim AA. Antibacterial activity and mechanical properties of partially hydrolyzed sago starch-alginate edible film containing lemongrass oil. Journal of Food Science. 2007 Aug 1;72(6):C324-30.

24. Moradi M, Tajik H, Rohani SM, Oromiehie AR, Malekinejad H, Aliakbarlu J, Hadian M. Characterization of antioxidant chitosan film incorporated with Zataria multiflora Boiss essential oil and grape seed extract. LWT-Food Science and Technology. 2012 May $31 ; 46(2): 477-84$.

25. American Society for Testing and Materials (ASTM) E96-80, Standard Test Methods for Water Vapor Transmission of Materials, 1984.

26. Luyt AS, Geethamma VG. Effect of oxidized paraffin wax on the thermal and mechanical properties of linear low-density polyethylene-layered silicate nanocomposites. Polymer Testing. 2007 Jun 30;26(4):461-70. 